\title{
Reflexões sobre o Consumo em Redes Digitais: um Ensaio Acerca das Interações entre Redes Sociais, Digital Influencers e Usuários
}

\section{Reflections on Consumption in Digital Networks: an Essay about Interactions between Social Networks, Digital Influencers and Users}

\author{
Lucas Lopes Ferreira de Souza \\ Universidade de Fortaleza - UNIFOR - Brasil \\ lucaslfsouza@unifor.br \\ ORCID: 0000-0001-9663-6086 \\ Nicoli Wanderley Amaral \\ Universidade Estadual do Ceará - UECE - Brasil \\ ni.amaral@gmail.com \\ ORCID: 0000-0003-3679-8061 \\ Carlos Dias Chaym \\ Universidade Estadual do Ceará - UECE - Brasil \\ carlosd.chaym@yahoo.com.br \\ ORCID: 0000-0002-8685-4650 \\ Felipe Gerhard \\ Universidade Estadual do Ceará - UECE - Brasil \\ gerhard.sousa@aluno.uece.br \\ ORCID: 0000-0002-1117-5960 \\ Francisco Roberto Pinto \\ Universidade Estadual do Ceará - UECE - Brasil \\ roberto.pinto@uece.br \\ ORCID: 0000-0003-2559-1524
}

Submetido em 22/04/2020; Aprovado em 23/09/2020.

\section{Resumo}

Objetivos do estudo: 0 objetivo deste ensaio é refletir sobre o processo de construção do consumo nas redes sociais on-line, focando, em especial, nas relações entre usuários, digital influencers e mídias digitais. Metodologia/abordagem: Para o estudo das malhas de relações ocorridas nas redes sociais online, a perspectiva do construtivismo social foi utilizada. Distanciando-se dos paroxismos objetivistas e subjetivistas das correntes modernas, o construtivismo social confere um maior poder de explicação à formação das redes socais por se embasar em uma perspectiva intersubjetiva. Principais resultados: A cocriação dos atores e o intercâmbio perene de informações entre eles conferem às redes sociais uma formação de caráter polissêmico e participativo. Entretanto, essa relação acabou por proporcionar o surgimento de uma cultura de consumo imanente, concedendo ao marketing uma função de mediador na criação dos significados e sentidos sociais. Além de discorrer sobre a distinção entre o consumo físico tradicional e o virtual, um modelo de interação entre os atores das redes sociais é apresentado. Contribuições acadêmicas: A partir da reflexão sobre as interações entre os atores, é sugerido um modelo relacional de construção de redes virtuais que contribui para a literatura ao proporcionar uma forma integrada de entender o desenvolvimento das relações de cocriação das mídias sociais com base no construtivismo social. Contribuições práticas: São sugeridas novas agendas de pesquisa, evidenciando-se que o consumo em ambientes digitais possui diferenças marcantes em relação ao consumo físico tradicional. A contínua interação entre os seus atores garante a ubiquidade do processo de cocriação digital, trazendo efeitos práticos para a gestão de marketing e o consumo virtual.

Palavras-chave: Redes sociais; Consumo; Construtivismo social.

\section{Abstract}

Objectives: the purpose of this essay is to reflect on the process of building consumption in online social 
networks, focusing in particular on the relationships between users, digital influencers and digital media. Methodology/approach: In order to study the meshes of relationships present in on-line social networks, the social constructionism approach was chosen. Distancing itself from the objectivist and subjectivist paroxysms of modern currents, social constructivism grants greater explanatory power to the formation of social networks because it is based on an intersubjective perspective. Main results: Actor's co-creation, and the ongoing interchange of information among them, provides to the social networks a polysemic and participative formation. However, it ends up promoting the emergence of an immanent consumption culture, conceding to marketing the function of the creation of social meanings and senses. Besides the distinction between the traditional physical consumption and the virtual one, an interaction model among social network actors is presented. Academic contributions: Based on the reflection on the interactions between the actors, a relational model for building virtual networks is suggested, which contributes to the literature by providing an integrated way of understanding the development of social media co-creation relationships based on the social constructivism. Practical contributions: New research agendas are suggested, showing that consumption in digital environments has marked differences in relation to traditional physical consumption. The continuous interaction between its actors guarantees the ubiquity of the digital co-creation process, bringing practical effects to the management of marketing and virtual consumption.

Keywords: Social networks; Consumption; Social constructivism.

\section{Introdução}

O debate sobre a formação do sujeito social tem se apoiado em diferentes perspectivas e correntes teóricas. Seria o homem independente das condições sócio-históricas de sua época e, portanto, responsável por desenvolvê-las? Ou seria ele apenas um reflexo do seu contexto social? Questões como essas foram sendo formuladas em consonância com características sui generis das relações sociais cotidianas, marcadas pela pessoalidade do contato vis-à-vis e das nuances próprias de cada contexto cultural.

Nesse contexto, duas correntes modernas surgiram apresentando abordagens ontológicas distintas. Segundo a perspectiva da economia clássica e das vertentes neoclássicas mais atuais, o homem apresenta total autonomia e liberdade em relação a externalidades tanto econômicas quanto sociais, sendo ele inteiramente responsável pelas decisões e atividades que exerce. Nessa abordagem, o homem seria um mero processador de informações, e como tal, teria capacidade similar à de seus pares no processo de formação pessoal (Earl, 1990). Totalmente isolado e independente, seja de outrem ou dos próprios fatores sócio-históricos, o indivíduo é entendido de forma atomizada dentro de uma perspectiva sistêmica; ou seja, juntamente com os demais indivíduos, ele seria o elemento responsável pela construção das evoluções históricas. Não seriam, portanto, as relações e nuances sociais que formariam o homem, mas ao contrário, seria ele o responsável por originar as mudanças na história (Tocquville, 2014).

De modo antagônico, uma abordagem onto-epistemológica se insurgiu contra essas doutrinas atomistas, lançando mão de perspectivas teóricas totalizantes para a compreensão da construção sóciohistórica. 0 materialismo histórico, proposto por Marx (2013), inaugurou um modo radical de entendimento da sociedade e das suas revoluções. Embasando-se nos princípios dialéticos hegelianos, mas dispensando a sua concepção ontológica idealista, Marx propunha uma inversão total no modo de encarar a relação entre homem e sociedade: os fatores sócio-históricos, em especial as lutas de classes, ocasionadas pela natureza contraditória da infraestrutura produtiva, são os reais responsáveis pela formação da consciência do sujeito.

Entretanto, ambas as perspectivas buscam explicar a formação das relações sociais dentro de um contexto físico tradicional, no qual os sujeitos, entendidos de modo atomizado, se relacionam por meio de interações episódicas e bem delimitadas (Cooper \& Burrell, 1980). Tanto os sujeitos quanto os próprios fatores sociais são reificados, o que transforma a interação entre eles em relações de causa e efeito (Cunliffe, 2008). No contexto dos ambientes on-line, as duas perspectivas apresentam sérias fragilidades, principalmente, por assumirem ou uma espécie de estabilidade inabalável e inata ao indivíduo ou uma supremacia de abstrações sociais sobre ele (Ritzer, 2014; 2015).

No que concerne especificamente às relações de mercado, os ambientes virtuais apresentam uma complexidade mais acentuada, difícil de ser apreendida pelos paradigmas modernistas (Cova \& Cova, 2012). Diferentemente das relações tradicionais, o contato entre os agentes de mercado nesses ambientes é mais intenso e contínuo, promovendo a formação de relações embasadas em componentes ideológicos, simbólicos e em valores pessoais, além de afetar mais contundentemente o consumidor por meio 
da persuasão e da sugestionabilidade (Chu \& Kim, 2011). Nessas redes, são transladados interesses, significados e sentidos por meio de intensas negociações entre atores que não possuem papéis estáveis ou pré-definidos, em um processo de cocriação ininterrupta (cf. Latour, 1999; Ritzer, 2015). Nesse ambiente on-line, a figura do prosumer ganha destaque, uma vez que as práticas de produção e consumo não são mais facilmente isoláveis (Ritzer \& Jurgenson, 2010; Anderson, Hamilton, \& Tonner, 2016). Dentro desse enredo, a perspectiva onto-epistemológica do construtivismo social se apresenta como uma fonte de análise com contribuições distintas das concepções anteriores, uma vez que busca fugir de uma análise estrutural do contexto social em detrimento de uma abordagem processual (Cunliffe, 2010; Cova \& Cova, 2012).

Nesse cenário, trabalhos anteriores têm se restringido a investigar fatores pontuais na relação de consumo em mídias sociais, como o papel dos líderes de opinião (Chu \& Kim, 2011; Bergström \& Belfrage, 2018; Luqiu, Schmierbach, \& Ng, 2019, Turcotte, York, Irving, Scholl, Pingree, 2015), materialismo (Fitzmaurice \& Comegys, 2006; Lou \& Kim, 2019), comportamento de compra compulsivo (Attiq \& Azam, 2015; Zheng, Yang, Zhou, Niu, Liu, \& Zhou 2020) ou até mesmo como a relação entre usuário e referências sociais pode afetar o seu bem-estar e saúde mental (Argo, White, \& Dahl, 2006; Poynor, 2010; Forest \& Wood, 2012; Nesi \& Prinstein, 2015; Stawarz, Preist, \& Coyle, 2019; Viner et al., 2019). Entretanto, nenhum estudo buscou investigar a construção do contexto de consumo por meio das interações entre usuários, mídias sociais e referências de consumo. Por meio delas, vínculos de mercado são criados e reformulados continuamente, ajudando a dilatar ainda mais as relações econômicas nas redes virtuais.

Baseando-se nos aportes teóricos apresentados, o objetivo geral deste ensaio é refletir sobre o processo de construção do consumo nas redes sociais, focando, em especial, nas relações entre usuários, digital influencers e mídias digitais por meio da abordagem do construtivismo social. Como objetivos específicos, serão analisados os aspectos metateóricos que sustentam essas relações com o intuito de se construir um modelo que discrimine as propriedades desse relacionamento.

\section{Mídias sociais}

As mídias sociais são tecnologias ou plataformas digitais, apresentadas como aplicativos e sites, que fornecem aos usuários ambientes nos quais eles podem enviar e receber conteúdo digital ou informações em algum tipo de rede social on-line, como Facebook, Instagram ou Twitter (Appel, Crusius, \& Gerlach, 2020). De forma mais ampla, tais ambientes se tornaram locais onde as pessoas conduzem partes significativas de suas vidas. Os usuários desse tipo de mídia a utilizam para gerar informações e compartilhar experiências com amigos, empresas e comunidades on-line por meio de postagens, compartilhamentos, curtidas e avaliações (Bailey et al., 2018, Martín-Consuegra, Díaz, Gómez, \& Molina, 2018). As mídias sociais se constituem um ecossistema centrado na tecnologia, no qual um conjunto diverso e complexo de comportamentos, interações e trocas pode ocorrer, envolvendo vários tipos de atores interconectados (Appel, Crusius, \& Gerlach, 2020).

Nesse contexto, além de mudar a forma como as pessoas vivem, aprendem e se conectam umas às outras (Quan-Haase \& Young, 2010; Van Dijck, 2012; Gruzd, Paulin, \& Haythornthwaite, 2016), as mídias oferecem oportunidades de construção e fortalecimento de relacionamentos sociais e profissionais com amigos, família e até mesmo empresas (Anderson, Hamilton, \& Tonner, 2016; Jacobson; Gruzd; Hernández-García, 2020). Por isso, no setor privado, a mídia social passou a ser frequentemente utilizada como ferramenta de comunicação para promover e vender produtos e serviços, sendo, assim, amplamente adotada como ferramenta de marketing (Kapoor, Tamilmani, Rana, Patil, Dwivedi, \& Nerur, 2018). 0 marketing de mídia social é usado em diversos setores do mercado e se refere à "utilização de tecnologias de mídia social, canais e software para criar, comunicar, entregar e trocar ofertas que tenham valor para as partes interessadas de uma organização" (Tuten \& Solomon, 2017, p. 18).

Assim, motivado tanto pela necessidade de exposição como de relacionamento com o público, o número de pequenas e grandes empresas totalmente inseridas no ambiente de comunidades virtuais tornou-se cada vez maior. A competitividade evidenciou a importância da participação das empresas nessas mídias, levando a tecnologia a se inserir na atividade de comunicação organizacional, além de alterar as relações entre empresas, comunicadores e público. Isso ocorre pois, nas redes sociais, os usuários ao se expressarem e compartilharem conteúdo, compartem o poder de se comunicar com outros usuários, poder antes exclusivo às organizações e aos veículos tradicionais de mídia (Becker, 2013). Desta forma, as redes sociais abriram espaço para que o consumidor possa ser mais interativo e ir além 
do ato de consumir, tornando-se também um produtor de conteúdo (Ritzer, 2015; Anderson, Hamilton, \& Tonner, 2016; Eden, 2017).

\section{A relação usuário e mídia}

No ambiente da Web 2.0, as redes sociais estão ligadas a serviços tecnológicos e softwares que possibilitam que as pessoas se comuniquem com outras pessoas de qualquer lugar e a qualquer momento. As redes sociais são espaços que podem ser personalizados por seus usuários, proporcionando a criação de perfis pessoais que possibilitam o desenvolvimento de conexões com outrem (Gunawardena, Hermans, Sanchez, Richmond, Bohley, \& Tuttle, 2009; Kapoor et al., 2018). Existe um acordo comum no setor da Web de que o termo Web 2.0 se refere a plataformas que são altamente interativas e que proporcionam aos usuários a capacidade de integrar diferentes mídias dentro da criação de conteúdo. Enquanto a Web 1.0 caracterizou-se por comunicações passivas e unidirecionais, a Web 2.0 é tipificada por um processo no qual as pessoas são simultaneamente criadoras e destinatárias de informações (Williams, Crittenden, Keo, \& McCarty, 2012).

Basicamente, um consumidor tem uma opinião sobre um produto ou serviço e compartilha esses pontos de vista, crenças e experiências com outras pessoas através da web (Ahuja, Michels, Walker, \& Weissbuch, 2007; Appel, Crusius, \& Gerlach, 2020). Este conteúdo gerado pelo consumidor pode aparecer sob a forma de depoimentos sobre a experiência com a marca, avaliações de produtos ou anúncios (Steyn, Wallström, \& Pitt, 2010). 0 conteúdo fornecido pelos consumidores tem atraído a atenção de profissionais de marketing e pesquisadores por uma série de razões (Steyn, Wallström, \& Pitt, 2010; Wang, Huang, \& Davison, 2020). Primeiro, o diferencial de custo entre o conteúdo criado por uma agência profissional e o gerado por um usuário pode ser considerável. Em segundo lugar, a forma de divulgação não convencional pode romper a saturação de mídia que prevalece atualmente. Em terceiro lugar, o boca a boca eletrônico pode se mover muito mais rápido para o consumidor do que a publicidade tradicional.

Além disso, alguns autores entendem que mensagens geradas pelos usuários, como descobertas compartilhadas, experiências e opiniões, são mais confiáveis se comparadas a mensagens corporativas por serem percebidas como experiências próprias dos consumidores, sem qualquer motivação comercial (Wu \& Wang, 2011; Filieri \& Mcleay, 2014; Wang, Huang, \& Davison, 2020). 0 marketing boca a boca sempre desempenhou um papel fundamental na comunicação devido à credibilidade adicional que proporciona, e, por isso, tem uma grande influência na opinião dos consumidores seja em meio físico, seja em virtual (Coll \& Micó, 2019).

Com efeito, as mídias virtuais passaram a apresentar uma matriz de construção social ainda mais atuante, com uma participação decisiva de todos os envolvidos. Não existe mais a delimitação de funções na web, os indivíduos ao mesmo tempo em que são consumidores são geradores de conteúdo, originando a figura dos prosumers (Ritzer, 2014; 2015). 0 termo surge da junção das funções de produtor e consumidor. Assim, o prosumer é um consumidor ativo, alguém capaz de dialogar, desempenhar papéis e integrar recursos e de projetar e até mesmo desenvolver produtos (Cova \& Cova, 2012; Dujarier, 2016). No ambiente on-line, o papel do prosumer ganha ainda mais relevância devido às facilidades de conexão com os demais usuários, possibilitando o surgimento de coproduções colaborativas e ressignificações de antigos conceitos (Anderson, Hamilton, \& Tonner, 2016).

Desse modo, vários pressupostos tradicionais de constituição da vida social são questionados, dando lugar a uma construção baseada na linguagem e no discurso. Temas importantes para uma compreensão mais densa da atividade do usuário na Web 2.0 incluem: o caráter semiótico e ilocucionário do discurso humano; o impulso à integridade etnometodológica na pesquisa social; e o foco na construção mútua do significado como a principal unidade de análise (Hackley, 1998; Ritzer, 2015).

As propriedades mediadoras da rede social criam contextos sociodigitais e condições para que a significação e comunicação aconteçam. Por sua vez, a participação social e a interação na rede social ganham uma possibilidade diferente de expressão e ação sobre o consumo. Isso significa que o consumo era diferente antes porque as condições em que os indivíduos atuavam eram diferentes. Por condição nos referimos ao contexto (físico e social), bem como à linguagem (mídia) e às possibilidades de significação (cognição, ação e interpretação) da prática social do consumo. A experiência de consumo é reescrita sobre uma nova maneira de se comunicar entre si (Cova \& Cova, 2012). Essas propriedades permanecem invisíveis e pouco estudadas, em parte porque é próprio da mídia cair em segundo plano e ser tomada por certo, mediando artificialidades como se fossem naturais (Alaimo, 2014). 
Por conseguinte, eis que surge o que se pode denominar de contexto digital social, em que se tem a atuação conjunta dos usuários e da mídia social. Juntos, constroem uma nova forma de consumo, na qual os usuários passam a ser conhecidos como prosumers, pois, além de consumidores, desempenham função de produção ao gerar conteúdo digital. Ao atuarem na construção de suas redes, tais consumidores se caracterizam como trabalhadores sociais, adicionando valor a suas identidades e relações sociais por meio de uma construção ativa, voluntária e criativa (Dujarier, 2016; Anderson, Hamilton, \& Tonner, 2016). Nesse contexto, a mídia se adapta para atender a demanda dos seus usuários e facilitar todo o processo de consumo (Alaimo, 2014)

\section{Digital influencers}

Os influenciadores de mídia social são personalidades on-line com grande número de seguidores em uma ou mais plataformas de mídia social, que vêm ganhando notoriedade por exercerem influência sobre demais usuários (Jiménez-Castillo \& Sánchez-Fernández, 2019; Wang, Huang, \& Davison, 2020). Ao contrário das celebridades ou figuras públicas que são conhecidas nas mídias tradicionais, os influenciadores das mídias sociais são "pessoas normais" que se tornaram "celebridades on-line", criando e postando conteúdo nas mídias sociais. Eles, geralmente, têm algum conhecimento em áreas específicas, como vida saudável, viagens, alimentação, estilo de vida, beleza ou moda e se envolvem em atividades focadas na oferta de conteúdo persuasivo para gerar engajamento, vendas e preferência de marca (Lou \& Yuan, 2019). Representam, assim, um novo tipo de formador de opinião, com um enorme potencial de rede e poder de influência sobre os consumidores (Uzunoğlu \& Kip, 2014; Cotter, 2019).

Os digital influencers nascem da interação entre a mídia e os usuários, porém atuam como líderes de opinião uma vez que utilizam a mídia com o intuito de repassar informações. A identificação de pessoas com habilidade para influenciar a opinião de muitos é bem mais antiga do que o fenômeno dos influenciadores digitais. Existe uma ampla literatura na área de comunicação sobre líderes de opinião (Hyman, 1960; Jones, 2002; Fawkes, 2004; Mcelreath \& Blamphin, 1994; Nisbet \& Kotcher, 2009; Vandermerwe \& Heerden, 2009; Aghdam \& Navimipour, 2017; Bergström \& Belfrage, 2018; Luqiu, Schmierbach, \& Ng, 2019). Katz e Lazarsfeld (1955), antes mesmo do surgimento da internet, já definiam esse tipo de líder como indivíduos que tinham a capacidade de influenciar outras pessoas em seu ambiente. Contudo, foi dentro do contexto das mídias sociais da internet que esses formadores de opinião receberam o nome de influenciadores digitais (Araújo, Neijens \& Vliegenhart, 2017).

Digital influencers são indivíduos importantes em redes sociais por causa de sua capacidade de influenciar informalmente as atitudes ou o comportamento de outros de uma maneira desejada e com frequência relativamente alta (Djafarova \& Rushworth, 2017). Para o marketing, essa influência pode ser usada para fins comerciais. Especificamente por meio do boca a boca, um influenciador digital pode fornecer informações sobre produtos, prover recomendações, dar comentários pessoais e complementar o conhecimento profissional para ajudar uma empresa a promover seus produtos (Uzunoğlu \& Misci, 2014; Cotter, 2019).

Para que tais influenciadores consigam se expressar de modo a alcançar o maior número de pessoas, é necessário que se utilizem de plataformas adequadas para tal. 0 ideal seria o uso de plataformas nas quais haja interação entre os participantes (Ma, Lee, \& Goh, 2014), como os blogs sociais on-line, que se constituem um bom canal através do qual esses líderes podem exercer sua influência (Li \& Du, 2011). Dessa forma, a plataforma exerce grande influência na forma como o líder de opinião se comunica com o usuário. A eficácia da comunicação se baseia não apenas na experiência do remetente, mas também na experiência do receptor, mudando a forma como a mensagem é percebida por diferentes pessoas (Bansal \& Voyer, 2000; Borchers, 2019).

Ma, Lee e Goh (2014) também salientam que a possibilidade de o usuário se enxergar como líder de opinião influencia na sua intenção em compartilhar notícias, pois essa autopercepção do líder como um influenciador no meio digital o induz a estar sempre compartilhando novas informações para manter sua influência. Logo, deve-se supor que há mais de um digital influencer dentro de um mesmo grupo e de uma plataforma. Como Weimann (1994) e Cotter (2019) apontam, os influenciadores tendem a ser interconectados, criando, assim, uma poderosa "rede invisível" que determina a adoção ou rejeição de inovações. Quando esses influenciadores possuem muitos contatos diretos e, também, estão mutuamente interligados, eles são considerados "próximos" de todos os outros membros do grupo (Appel, Crusius, \& Gerlach, 2020). Assim, como outros tipos de líderes de opinião, os digital influencers podem disseminar inovações e gerar tendências devido ao seu amplo potencial de alcance (Kratzer \& Lettl, 
2009).

Os digitais influencers surgem como prosumers que se utilizam de seus conhecimentos para apresentar algo que dominam e consomem (Cova \& Cova, 2012; Anderson, Hamilton, \& Tonner, 2016). A partir da divulgação deste conhecimento, passam a atuar nas plataformas construindo relações virtuais e trabalhando, muitas vezes, inconscientemente para a rede social ao produzirem conteúdo (Dujarier, 2016; Anderson, Hamilton, \& Tonner, 2016). Nesse momento, o mercado deixa de ser "produzido para" consumidores e passa a ser "produzido por" consumidores, os quais passam a ser considerados parceiros das empresas presentes na rede (Cova \& Cova, 2012; Dujarier, 2016).

\section{Construtivismo social e a relação entre usuários, digital influencer e mídias sociais}

De forma simplificada, é possível dividir as correntes onto-epistemológicas na disciplina de marketing em dois subgrupos: as linhas objetivistas e subjetivistas. Para os objetivistas, em geral, a realidade se expressa independente do sujeito e se estruturaria de forma sistêmica, isto é, cada elemento é entendido de forma atomizada (Cooper \& Burrell, 1980). A filosofia subjetivista, por outro lado, não rejeita a possibilidade de existência de uma realidade externa, aos moldes do que propõem as correntes objetivistas. No entanto, o que os subjetivistas defendem e utilizam como base ontológica é o inevitável "experienciar" dessa realidade na mente das pessoas (Burrell \& Morgan, 1979).

A busca por uma alternativa às correntes objetivistas e subjetivistas é a base da formação do pensamento construtivista social. Segundo os seus pensadores, a "realidade" não possui uma estrutura definida, muito menos pode ser compreendida de forma independente da consciência humana. Significados, percepções e conhecimentos são relativos ao tempo, ao espaço e à maneira como são socialmente construídos - por meio das interações entre as pessoas presentes no dia a dia - (Cunliffe, 2010; Jung, 2019). 0 senso comum ganha para tais epistemologias status de conhecimento legítimo por se constituir dos relacionamentos e práticas cotidianas das pessoas. A criação de conceitos, que objetivam e individualizam entidades ou fenômenos abstratos, práxis do método objetivista, são evitados por conta dessa virada de perspectiva, voltando-se a micro aspectos e movimentos, bem como dando mais voz e importância às pessoas e suas vidas. Em consequência, os conhecimentos e "realidades" sociais não são duráveis, replicáveis, generalizáveis ou previsíveis, mas, ao contrário, são entendimentos contextualizados, evocativos e negociáveis (Cunliffe, 2008).

Dessa forma, o posicionamento do construtivismo social se embasa em uma ontologia intersubjetiva, compreendendo a "realidade" não como uma estrutura autônoma e independente da apreensão subjetiva das pessoas, mas formada por um processo de construção centrado na figura das relações sociomateriais (Cunliffe, 2008; Kwok \& Koh, 2020). Assim, é possível inferir que as interações humanas são responsáveis por parte do processo de construção do ambiente social, mas não de todo ele. Isso porque objetos materiais são constitutivos e não simplesmente um reflexo das relações sociais (Lefebvre, 1991). 0 contexto, portanto, é constituído e influenciado não apenas por humanos, mas também por elementos materiais (Latour, 1999). Ambos moldam a dialética intersubjetiva, uma vez que o social e o material estão integralmente entrelaçados na construção da vida diária (Orlikowski, 2009).

Deslocando essa discussão para as plataformas e ambientes virtuais, é possível destacar que a apropriação, a modificação e a vivência por seus usuários dos elementos materiais que as constituem são ainda mais flexíveis do que a dos ambientes físicos, o que tornam esses territórios mais dinâmicos e mutáveis. Os ambientes virtuais não dependem de locais particulares ou bens físicos para desenvolverem as suas interações (Dale, 2005). 0 mundo dos fluxos eletrônicos e das representações intangíveis prescinde, inclusive, da presença física dos próprios usuários humanos. Assim como no mundo físico, os objetos presentes no ambiente virtual por si só não criam significado social algum, mas a sua presença como "coisas do mundo" (Law \& Hetherington, 2000) é capaz de iniciar um processo de significação e ressignificação, possível apenas devido à sua materialidade constitutiva. Embora muitas das nossas experiências realizadas nos ambientes virtuais que transitamos no dia a dia sejam promovidas de forma tácita e irrefletida, elas não são construídas de forma natural ou uniforme. Há tanto uma organização quanto uma reprodução particular das relações presentes nesse contexto que conduzem os significados criados e compartilhados socialmente.

Não se trata, aqui, de compreender o usuário em sua completa subjetividade. Os humanos são apenas parte do mundo material e não deuses transcendentes capazes de manipular o mundo sem serem incorporados ou alterados por ele (Dale, 2005). A questão é entender como as subjetividades coabitam um mesmo (cyber) espaço, ou seja, como se constrói a intersubjetividade existente entre eles. No 
caso das mídias sociais, a relação dos usuários com outros atores, elementos virtuais, bem como com a própria mídia formam a rede de relações que os incorpora e orienta comportamentos e atitudes. Não é uma questão de discutir se o consumidor possui total autonomia ou se os estímulos externos influenciam as suas decisões, mas sim de entender o quanto o comportamento social pode sofrer influência e influenciar o seu contexto material. Sob essa perspectiva, todos os elementos presentes em uma mídia social interagem entre si e por meio das suas múltiplas relações formam e se apropriam do seu espaço.

Porquanto se caracterizem como ambientes deliberadamente criados para propósitos específicos, as mídias sociais possuem funções teleológicas que orientam e ordenam os seus elementos virtuais. Funções essas redefinidas pela ação e relação dos seus usuários. A discussão da sociomaterialidade é um ponto importante para indicar como os usuários, digital influencers e as próprias mídias virtuais influenciam e são influenciados pelos espaços sociais que vivenciam e constroem conjuntamente. Os usuários não apenas criam o espaço por meio das interações que realizam entre si, mas também são moldados pelas relações que engatam com a pluralidade de sujeitos e componentes postos à disposição nas mídias sociais em uma interação que vai além do debate da dualidade entre agência e estrutura social. Da interação presente nestes ambientes surgem os consumidores-produtores (i.e. prosumers) (Cova \& Cova, 2012), os quais se engajam em formas de trabalho social e colaborativo (Dujarier, 2016; Anderson, Hamilton, \& Tonner, 2016) por meio de plataformas virtuais orientadas para a criação de valor não apenas para os seus elementos constituintes, mas para a própria rede. (Anderson, Hamilton, \& Tonner, 2016; Eden, 2017). A Figura 1, apresentada a seguir, sintetiza graficamente essa interação constitutiva entre os componentes presentes nas mídias sociais.

Figura 1 - Modelo Relacional de Construção de Redes Virtuais

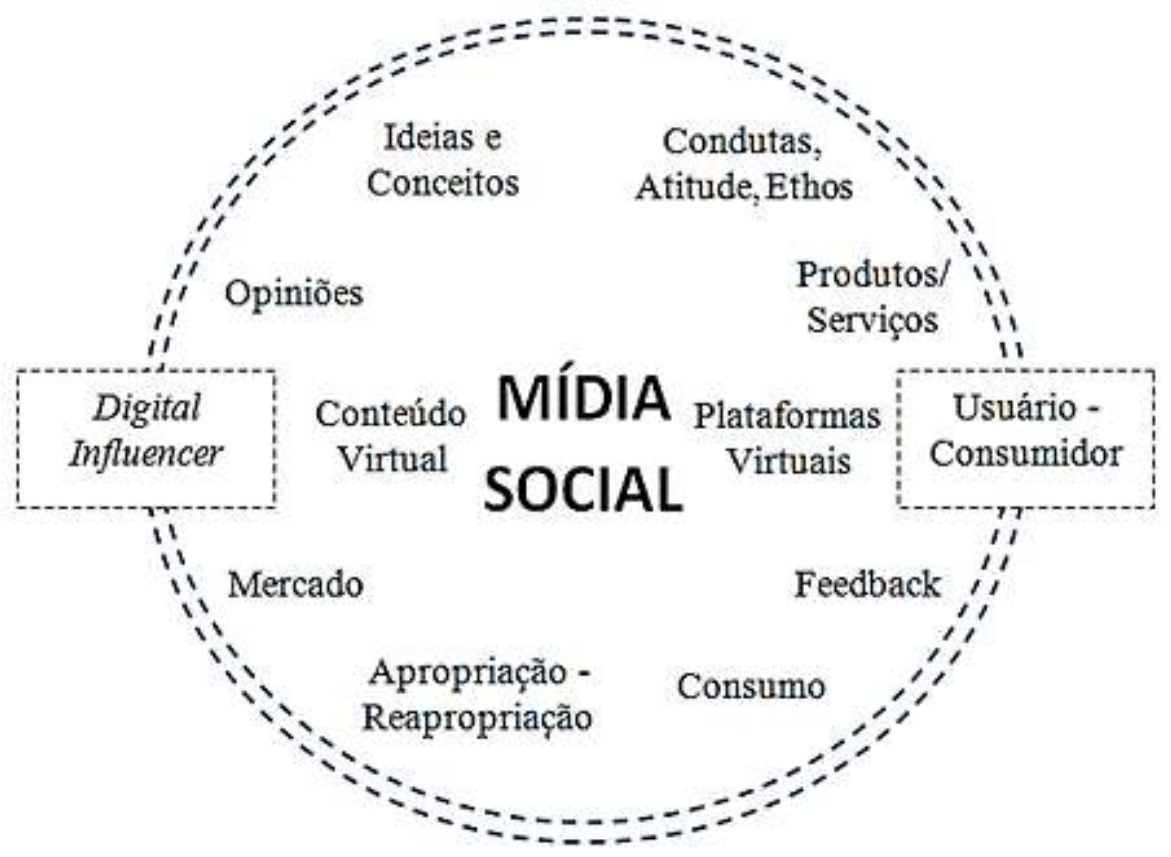

Fonte: Elaborado pelos autores.

Com base nos elementos onto-epistemológicos apresentados e em uma perspectiva de construção da realidade intersubjetiva, ou seja, priorizando as relações ao invés de se apreender uma suposta essência dos objetos ou dos sujeitos (Whitehead, 1985), é possível contrastar algumas das principais propriedades do ato de consumir tradicional, em contextos físicos, e o consumo em ambientes virtuais, mediado pelas redes e mídias sociais. 0 Quadro 1, a seguir, traça um paralelo entre as práticas de consumir nos dois cenários.

Quadro 1 - Paralelo entre Consumo Físico Tradicional e Consumo Virtual

\begin{tabular}{c|c|cc}
\hline Classes & Atributos & Consumo Físico Tradicional & Consumo Virtual \\
\hline $\begin{array}{c}\text { Bases Meta- } \\
\text { teóricas }\end{array}$ & $\begin{array}{c}\text { Perspectiva Onto- } \\
\text { epistemológica }\end{array}$ & $\begin{array}{c}\text { Modernismo - Reificação dos atores pre- } \\
\text { sentes no mercado. Consumidor e em- } \\
\text { presa são objetivados e possuem orienta- } \\
\text { ções racionalizadas. }\end{array}$ & $\begin{array}{c}\text { Construtivismo Social - Foco nas rela- } \\
\text { ços. Consumidores, influencers e mí- } \\
\text { dias se entrelaçam para formar redes e } \\
\text { arranjos virtuais. }\end{array}$ \\
\hline
\end{tabular}




\begin{tabular}{|c|c|c|c|}
\hline \multirow{4}{*}{$\begin{array}{l}\text { Organização } \\
\text { de Mercado }\end{array}$} & Relações de troca & $\begin{array}{l}\text { Quid Pro Quo - momentos de troca bem } \\
\text { definidos por meio da permuta de com- } \\
\text { modities }\end{array}$ & $\begin{array}{l}\text { Momentos de troca ininterruptos, por } \\
\text { meio da cocriação de conteúdos e com- } \\
\text { partilhamento de valores, ideias e sen- } \\
\text { tidos }\end{array}$ \\
\hline & $\begin{array}{l}\text { Perspectiva Eco- } \\
\text { nômica }\end{array}$ & $\begin{array}{l}\text { Central - regula boa parte das interações } \\
\text { do mercado }\end{array}$ & $\begin{array}{c}\text { Periférica - mas se caracteriza como } \\
\text { elemento tácito que permeia as intera- } \\
\text { ções em rede }\end{array}$ \\
\hline & $\begin{array}{l}\text { Mecânica Produ- } \\
\text { tiva }\end{array}$ & $\begin{array}{l}\text { Funções de produção e consumo bem de- } \\
\text { limitadas e não intercambiáveis }\end{array}$ & $\begin{array}{l}\text { Baseia-se nos conceitos de cocriação e } \\
\text { prosumption. Funções intercambiáveis } \\
\text { e indissociáveis }\end{array}$ \\
\hline & $\begin{array}{l}\text { Operacionaliza- } \\
\text { ção }\end{array}$ & $\begin{array}{l}\text { Foco no produto ou serviço - reificação e } \\
\text { isolamento dos objetos de análise }\end{array}$ & $\begin{array}{c}\text { Foco nos relacionamentos: processo } \\
\text { contínuo de cocriação }\end{array}$ \\
\hline \multirow{5}{*}{$\begin{array}{l}\text { Aspectos In- } \\
\text { dividuais }\end{array}$} & $\begin{array}{l}\text { Identidade dos } \\
\text { Agentes }\end{array}$ & $\begin{array}{l}\text { Unitária - consumidor e empresa pos- } \\
\text { suem identidades bem delimitadas }\end{array}$ & $\begin{array}{l}\text { Fragmentada - agentes possuem múlti- } \\
\text { plas identidade: cocriadores, articula- } \\
\text { dores da rede etc. }\end{array}$ \\
\hline & $\begin{array}{l}\text { Hierarquia de Pa- } \\
\text { péis }\end{array}$ & $\begin{array}{l}\text { Fronteiras bem delimitadas. Organiza- } \\
\text { ções com maior poder nas relações }\end{array}$ & $\begin{array}{c}\text { Ausência de fronteiras rígidas e redu- } \\
\text { ção da desigualdade de poder }\end{array}$ \\
\hline & $\begin{array}{l}\text { Relações Indivi- } \\
\text { duais }\end{array}$ & $\begin{array}{l}\text { Interações estruturadas, hierarquizadas } \\
\text { e papéis bem definidos }\end{array}$ & $\begin{array}{l}\text { Relações flexíveis, expansão e instabili- } \\
\text { dade de papéis }\end{array}$ \\
\hline & $\begin{array}{l}\text { Acesso à Informa- } \\
\text { ção }\end{array}$ & $\begin{array}{l}\text { Limitado e assimétrico - organizações } \\
\text { detêm maior poder sobre a informação }\end{array}$ & $\begin{array}{c}\text { Ampliado - consumidores detêm maior } \\
\text { poder sobre as informações }\end{array}$ \\
\hline & $\begin{array}{l}\text { Decisão de Com- } \\
\text { pra }\end{array}$ & $\begin{array}{l}\text { Exposição a uma grande quantidade de } \\
\text { estímulos. Margem para processos mais } \\
\text { planejados de decisão de compra }\end{array}$ & $\begin{array}{l}\text { Exposição a uma imensa quantidade de } \\
\text { estímulos de compra. Decisões toma- } \\
\text { das de modo mais irrefletido e impul- } \\
\text { sivo }\end{array}$ \\
\hline \multirow{4}{*}{$\begin{array}{l}\text { Aspectos So- } \\
\quad \text { ciais }\end{array}$} & Relações Sociais & $\begin{array}{l}\text { Entre consumidor e organização - redu- } \\
\text { zido ou nenhum contato com outras pes- } \\
\text { soas }\end{array}$ & $\begin{array}{l}\text { Entre mídias, digital influencers e con- } \\
\text { sumidores - cocriadores }\end{array}$ \\
\hline & $\begin{array}{l}\text { Comunidades de } \\
\text { Consumo }\end{array}$ & Fechadas, hierarquizadas e inflexíveis & $\begin{array}{l}\text { Abertas e flexíveis, definidas por com- } \\
\text { partilhamento de práticas e intenções - } \\
\text { tribos e grupos de consumo }\end{array}$ \\
\hline & $\begin{array}{l}\text { Formas de Socia- } \\
\text { lização }\end{array}$ & Trocas mercadológicas de commodities & $\begin{array}{l}\text { Relações não reduzíveis ao território } \\
\text { mercadológico }\end{array}$ \\
\hline & $\begin{array}{c}\text { Relações de Tra- } \\
\text { balho } \\
\end{array}$ & Individual e para organizações & Colaborativa e em rede - prosumer \\
\hline
\end{tabular}

Fonte: Elaborado pelos autores.

\section{Proposições}

As discussões até então apresentadas não se propõem de modo algum a serem definitivas. Na visão dos autores deste trabalho, dada a complexidade, envergadura e relevância da intersubjetividade existente entre usuários, digital influencers e mídias sociais, diversas lentes podem ser utilizadas para observar esse fenômeno. Além disso, o fato de que a ação de cada um dos elementos envolvidos gera lastro nos demais, reconfigurando este arranjo, faz com que as discussões acerca deste assunto possam se valer de diferentes perspectivas teóricas. Esta seção traz uma relação inicial de abordagens que têm o potencial de explicar tais fenômenos de uma forma distinta do que foi apresentado neste estudo.

Um primeiro recorte proposto seria abordar a questão sob a ótica da Complexidade, uma vez que o cipoal de elementos que se desvelam na formação desse fenômeno pode ser estudado com foco nas reconfigurações que surgem como resposta à ação de um dos elementos e não há, em princípio, uma força determinante de um sobre o outro. Assim, as discussões das Teoria do Caos, Fractais, Teoria das Catástrofes e/ou Lógica Fuzzy poderiam ampliar a compreensão destes fenômenos a partir da consideração de que a interdependência das ações de elementos distintos geram reações em cadeias imprevisíveis (Desanctis \& Poole, 1994; Brown \& Eisenhardt, 1997; Anderson, 1999; Law \& Mol, 2002). Nesta perspectiva, a tríade consumidor-mídias digitais-digital influencers poderia ser vista, por exemplo, como um sistema adaptativo complexo.

Outro recorte possível de análise pode ser obtido utilizando-se o Modelo EntidadeRelacionamento (MER) proposto inicialmente por Peter Chen. Para este autor, "o modelo entidaderelacionamento adota a visão mais natural de que o mundo real é composto de entidades e relacionamentos" (Chen, 1976, p. 9). Neste modelo, os processos que ocorrem entre as entidades são clarificados a partir de uma sistematização da estrutura da informação de tal modo a produzir um relacionamento único entre as partes (Chen, 1976; 1983; Batini \& Lenzerini, 1984; Elmasri, Weeldreyer, 
\& Hevner, 1985; Liu \& Özsu, 2009).

Essa concepção se assemelha com o fluxo de informação gerado entre os usuários da internet, as mídias digitais e os digital influencers. Estudos que investiguem tais relações utilizando o Modelo Entidade-Relacionamento têm o potencial de classificar as relações e torná-las mais facilmente rastreáveis e compreensíveis. Contudo, esta visão estrutural das relações e o caráter unirelacional pode trazer consigo viéses de pesquisa ao engessá-las e mitigar as intersubjetividades existentes entre as entidades.

Já a Teoria Ator-Rede é uma abordagem que permite rastrear de forma mais fluida as relações entre atores que se associam para a formação de redes. Essa abordagem tem como pressuposto a concepção de que "social" é um emaranhado de atores que se agrupam para formar redes relacionais capazes de produzir fenômenos distintos (Latour, 1994; 1999; 2012; Latour \& Woolgar, 1997; Law, 1992; 1994). Sob essa ótica, a ação é vista sempre como um processo de translação idiossincrática que integra não apenas atores humanos, mas também elementos não-humanos e/ou híbridos para formar redes-de-atores (Latour, 1999).

Do mesmo modo, uma forte tendência em estudos de gestão e organizações é a investigação de fenômenos por meio de abordagens historiográficas, ressaltando aspectos retrospectivos da formação das redes (Clark \& Rowlinson, 2004; Bell \& Taylor, 2013). As relações intersubjetivas que se formam entre as mídias digitais, usuários e influenciadores podem ser analisadas a partir do modo como essas relações foram produzindo a história dos eventos estudados. Oriunda da inserção da Teoria Ator-Rede nas discussões da chamada virada histórica em estudos organizacionais, a ANTi-History, proposta por Durepos (2009) e Durepos e Mills (2012), é uma abordagem historiográfica que permite investigar a formação dos fatos, fenômenos e coisas por meio do rastreamento do passado sociopolítico dos atoresem-rede.

Outro ponto a ser abordado são os possíveis efeitos negativos das relações virtuais. Em ambientes marcados pela ausência de legislações claras, nos quais os controles sociais costumam ser exercidos por meio de regras tácitas, dominações e vantagens podem surgir. De fato, há uma dupla vantagem (double exploitation) sobre os prosumers nas redes sociais, uma vez que além de adquirir produtos por preços premium (eventualmente inflados artificialmente), não participam dos ganhos propiciados por suas próprias produções coletivas (Cova \& Cova, 2012; Ritzer, 2014; 2015). Em relação às empresas, ademais, a instabildiade dessa relação pode trazer sérias consequências desde o boca a boca negativo a retaliações, boicotes e sabotagens às organizações ou às redes sociais (Kähr, Nyffenegger, Krohmer, \& Hoyer, 2016). Do mesmo modo, pode ensejar o surgimento de novos competidores capazes de captar com mais eficiência as necessidades e desejos cocriados pelos consumidores (Vargo \& Lusch, 2004; Cova \& Cova, 2012).

Cabe ressaltar que a tarefa de listar abodagens possíveis para o estudo de ambientes virtuais e seu universo não se limita ao que foi proposto até então. Para investigar tais intersubjetividades, é convidativo pensar na contribuição de teorias de outras áreas do conhecimento, como Psicologia, Geografia Humana, Ciência Social, Filosofia, para citar apenas algumas.

\section{Reflexões finais}

Além de uma ampliação sem precedentes das fronteiras relacionais, as redes e mídias sociais provocaram uma transformação no modo de consumir e atingir grandes públicos. 0 consumo, que até então se configurava como uma ação pontual e discreta - na qual se identificava de forma aparentemente clara todas as etapas do processo de consumo, desde a compra até o descarte de um produto ou conclusão de um serviço -, passa a ser um elemento tácito que permeia os ambientes virtuais. Com isso, ele ganha status de imanência, ratificando o papel de cocriação do consumidor. Essa virada nas práticas de consumir torna o usuário não apenas um mero receptor passivo de produtos acabados em um processo de simples satisfação de necessidades, mas um agente ativo na produção de conteúdo, ideias e valores compartilhados na rede.

As redes virtuais, desse modo, suscitam uma mudança radical na forma de encarar o relacionamento entre consumidores, empresas e mercado. Os agentes desse dinâmico e plural território mercadológico se tornam atores igualmente importantes na construção de necessidades, desejos e significados sociais. Essa ampliação da ação do consumidor é perceptível ao se observar o contexto empírico das redes e mídias sociais, o qual também ratifica um processo multilateral de construção de significados por meio de uma matriz social. As redes fazem emergir, portanto, os preceitos de uma cocriação coletiva 
de valor, a qual se embasa em uma construção social polissêmica e perene.

Embora agentes até então enfraquecidos nos mercados tradicionais tenham ganhado poder nas mídias virtuais, o marketing ganha ainda mais destaque como elemento central das relações sociais. 0 marketing (não como ciência, mas enquanto efeito das instâncias do poder organizacional) deixa de representar apenas um momento no processo cultural de construção de significados para ter uma influência ainda maior, cortejando transformar-se nesse próprio processo de construção de significados. Ele sustenta um conjunto de valores, signos e símbolos sociais, ajustando e distribuindo os significados socialmente construídos. Mais do que isso, ao passo que agrupa e aproxima opiniões e pessoas em comum, ele perigosamente as rotula, discrimina e rivaliza. As redes sociais, portanto, expandiram o potencial de influência do marketing por estarem integralmente embasadas em imagens e símbolos, despertando aspectos afetivos e inconscientes ao invés de promover a razoabilidade no processo de compra. Por outro lado, tal movimento pode comprometer a estabilidade das empresas nesses contextos. Isso porque a dinâmica das construções de significados coletivos pelos prosumers expõe a fragilidade das organizações em controlar seus valores, identidades e imagem de marcas nas redes sociais.

Dessa forma, o debate para um novo entendimento da relação entre agência e estrutura se torna ainda mais relevante dentro desse contexto, uma vez que os contornos divisórios entre o que é estímulo de consumo - conteúdo, produtos e serviços - e autonomia criativa do usuário é insipiente ao ponto de serem indissossiáveis. Apesar do intenso uso de processos criativos, facultados por uma maior liberdade e velocidade de ação nas redes sociais, as movimentações em tais ambientes não são realizadas sem influência de outros agentes. Usuários, mídias e digital influencers contribuem para a construção das redes, transformando-as em um território de alianças, negociações e cocriações. Nessa perspectiva, consumo e produção são duas faces de uma mesma moeda, dois aspectos que se complementam e dependem um do outro, destacando ainda mais o papel dos prosumers no contexto virtual. Tanto o conundrum entre agência e estrutura quanto a questão da cocriação nas redes sociais são temas ainda pouco abordados na área de marketing, em especial em trabalhos nacionais, o que oporuniza o surgimento de novos estudos na área.

Do mesmo modo, a análise da ação do marketing como um dos agentes influenciadores centrais nas redes sociais se caracteriza como um tema relevante de pesquisa. Embora tenha sido exaustivamente estudado ao longo das últimas décadas com o intuito de se explorar e se apropriar dos atributos mercadológicos das redes sociais, poucos estudos apresentam uma postura mais crítica sobre o papel do marketing nesses ambientes. Como sugestão final para pesquisas futuras, sugere-se a aplicação do modelo teórico proposto no estudo por meio de pesquisas empíricas. Do mesmo modo, sugere-se o uso de perspectivas epistemológicas e teóricas distintas, buscando-se ampliar o debate e a contribuição conceitual para o tema. A corrente onto-epistemológica que guiou a condução deste ensaio, o construtivismo social, é apenas mais uma maneira de se compreender os contornos e as formas de relação presentes nas redes sociais.

\section{Referências}

Aghdam, S. M. \& Navimipour, N. J. (2016). Opinion leaders selection in the social networks based on trust relationship propagation. Karbala International Journal of Modern Science, 2(2), 88-97.

Ahuja, R. D., Michels, T. A., Walker, M. M., \& Weissbuch, M. (2007). Teen perceptions of disclosure in buzz marketing. Journal of Consumer Marketing. 24(3), 151-159.

Alaimo, C. (2014). Computational Consumption: Social media and the construction of digital consumers (Doctoral dissertation, The London School of Economics and Political Science (LSE)).

Anderson, P. (1999). Perspective: Complexity Theory and Organization Science. Organization Science, 10(3), 216-232.

Anderson, S., Hamilton, K., \& Tonner, A. (2016). Social labour: Exploring work in consumption. Marketing Theory, 16(3), 383-400.

Appel, G., Grewal, L., Hadi, R., \& Stephen, A. T. (2020). The future of social media in marketing. Journal of the Academy of Marketing Science, 48(1), 79-95.

Bansal, H. S. \& Voyer, P. A. (2000). Word-of-mouth processes within a services purchase decision context. Journal of service research, 3(2), 166-177.

Bailey, C. M. Bonifield, A. (2018). Social media use by young Latin American consumers: an exploration. Journal of Retailing and Consumer Service, 43, 10-19.

Becker, V. (2013). A evolução da interatividade na televisão: da TV analógica à era dos aplicativos. 
Lumina, 7(2), 1-30.

Bell, E. \& Taylor, S. (2013). Writing history into management research. Management \& Organizational History, 8(2), 127-136.

Bergström, A., Belfrage, M. J. (2018). News in Social Media. Digital Journalism, 6(5), 583-598.

Borchers, N. S. (2019) Social Media Influencers in Strategic Communication, International Journal of Strategic Communication, 13(4), 255-260.

Brown, S. \& Eisenhardt, K. (1997). The Art of Continuous Change: Linking Complexity Theory and TimePaced Evolution in Relentlessly Shifting Organizations. Administrative Science Quarterly, 42(1), 1-34. Burrel, G. \& Morgan, G. (1979). Sociological Paradigms and Organisational Analysis. Aldershot: Gower.

Chan, K. \& Misra, S. (1990). Characteristics of the opinion leader: A new dimension. Journal of advertising, 19(3), 53-60.

Chen, P. (1976). The entity-relationship model: towards a unified view of data. ACM Trans. Database Systems, 1(1), 9-36.

Chen, P. (1983). English Sentence Structure and Entity-Relationship Diagrams. Information Sciences, 29, 127-149.

Clark, P \& Rowlinson, M. (2004). The treatment of History in Organization Studies: to-wards an 'historic turn? Business History, 46(3), 331-352.

Cooper, R. \& Burrell, G. (1998). Modernism, postmodernism and organizational analysis: An introduction. Organization Studies, 9(1), 91-112.

Cotter, K. (2019). Playing the visibility game: How digital influencers and algorithms negotiate influence on Instagram. New Media \& Society, 21(4), 895-913.

Cova, B., \& Cova, V. (2012). On the road to prosumption: marketing discourse and the development of consumer competencies. Consumption Markets \& Culture, 15(2), 149-168.

Cunliffe, A. L. (2010). Crafting qualitative research: Morgan and Smircich 30 years on. Organizational Research Methods, 14(4), 647-673.

Cunliffe, A. L. (2008). Orientations to social constructionism: Relationally responsive social constructionism and its implications for knowledge and learning. Management Learning, 39(2), 123-139.

Dale, K. (2005). Building a social materiality: Spatial and embodied politics in organizational control. Organization, 12(5), 649-678.

Desanctis, G. \& Poole, M. (1994). Capturing the Complexity in Advanced Technology Use: adaptative structuration theory. Organization Science, 5(2), 121-147.

Dujarier, M. A. (2016). The three sociological types of consumer work. Journal of Consumer Culture, $16(2), 555-571$.

Durepos, G. (2009). ANTi-History: Toward an Historiographical Approach to (Re)assem-bling Knowledge of the Past. (Doctoral dissertation, Saint Mary's University).

Durepos, G. \& Mills, A. (2012). Actor-Network Theory, ANTi-History and critical organizational historiography. Organizations, 19(6), 703-721.

Earl, P. E. (1990). Economics and psychology: a survey. The Economic Journal, 100(402), 718-755.

Eden, S. (2017). Blurring the boundaries: Prosumption, circularity and online sustainable consumption through Freecycle. Journal of Consumer Culture, 17(2), 265-285.

Elmasri, R., Weeldreyer, J., \& Hevner, A. (1985). The category concept: An extension to the entity-relationship model. Data \& Knowledge Engineering, 1, 75-116.

Gruzd, A., Paulin, D., \& Haythornthwaite, C. (2016). Analyzing social media and learning through content and social network analysis: A faceted methodological approach. Journal of Learning Analytics, 3(3), 46-71.

Gunawardena, C. N., Hermans, M. B., Sanchez, D., Richmond, C., Bohley, M., \& Tuttle, R. (2009). A theoretical framework for building on-line communities of practice with social networking tools. Educational Media International, 46(1), 3-16.

Hackley, C. E. (1998). Social constructionism and research in marketing and advertising. Qualitative Market Research: An International Journal, 1(3), 125-131.

Jacobson, J., Gruzd, A., \& Hernández-García, Á. (2020). Social media marketing: Who is watching the watchers? Journal of Retailing and Consumer Services, 53. https://doi.org/10.1016/j.jretconser.2019.03.001.

Jiménez-Castillo, D. \& Sánchez-Fernández, R. (2019). The role of digital influencers in brand recommendation: Examining their impact on engagement, expected value and purchase intention. 
International Journal of Information Management, 49, 366-376.

Jung, H. (2019) The Evolution of Social Constructivism in Political Science: Past to Present. SAGE Open, 9(1), 1-10.

Kähr, A., Nyffenegger, B., Krohmer, H., \& Hoyer, W. D. (2016). When hostile consumers wreak havoc on your brand: The phenomenon of consumer brand sabotage. Journal of marketing, 80(3), 25-41.

Kapoor, K. K., Tamilmani, K., Rana, N. P., Patil, P., Dwivedi, Y. K., \& Nerur, S. (2018). Advances in social media research: Past, present and future. Information Systems Frontiers, 20(3), 531-558.

Katz, E. \& Lazarsfeld, P. F. (1965). Personal Influence: The Part Played by People in the Flow of Mass Communications. Free Press.

Kratzer, J. \& Lettl, C. (2009). Distinctive roles of lead users and opinion leaders in the social networks of schoolchildren. Journal of Consumer Research, 36(4), 646-659.

Kwok, A. O. J., Koh, S. G. M. (2020). Deepfake: a social construction of technology perspective. Current Issues in Tourism, 1-6. https://doi.org/10.1080/13683500.2020.1738357.

Latour, B. (1994). Jamais Fomos Modernos: Ensaio de Antropologia Simétrica. São Paulo: Editora 34.

Latour, B. (1999). Ciência em ação: como seguir cientistas e engenheiros sociedade afora. São Paulo: Editora Unesp.

Latour, B. (2012). Reagregando o Social: uma introdução à Teoria Ator-Rede. Bauru, São Paulo: Edusc.

Latour, B. \& Woolgar, S. (1997). A vida de laboratório: a produção dos fatos científicos. Rio de Janeiro: Relume Dumará.

Law, J. (1992). Notes on the Theory of the Actor-Network: Ordering, Strategy and Heterogeneity. Systems Practice, 5, 379-393.

Law, J. (1994). Organizing Modernity. Oxford, UK: Blackwell.

Law, J. \& Hetherington, K. (2000). Materialities, Spatialities, Globalities. In: Bryson, J. et al. (eds) Knowledge, Space, Economy. London: Routledge.

Law, J. \& Mol, A. (2002). Complexities: Social Studies of Knowledge Practices. Durham: Duke University Press.

Lefebvre, H. (1991). The Production of Space. Oxford: Blackwell.

Li, F. \& Du, T. C. (2011). Who is talking? An ontology-based opinion leader identification framework for word-of-mouth marketing in on-line social blogs. Decision Support Systems, 51(1), 190-197.

Liu, L \& Öszu, M. (2009). Encyclopedia of Database Systems. New York: Springer Science.

Lou, C. \& Kim, H. K. (2019). Fancying the New Rich and Famous? Explicating the Roles of Influencer Content, Credibility, and Parental Mediation in Adolescent's Parasocial Relationship, Materialism, and Purchase Intantions. Frontiers in Psychology, 10 (11), 2567, https://doi.org/10.3389/fpsyg.2019.02567.

Lou, C. \& Yuan, S. (2019). Influencer marketing: how message value and credibility affect consumer trust of branded content on social media. Journal of Interactive Advertising, 19(1), 58-73.

Luqiu, L. R., Schmierbach, N., \& Ng., Y. (2019). Willingness to follow opinion leaders: A casy study of Chinese Weibo. Computers in Human Behavior, 101, 42-50. https://doi.org/10.1016/j.chb.2019.07.005.

Ma, L., Lee, C. L., \& Goh, D. H. L. (2014). Understanding news sharing in social media: An explanation from the diffusion of innovations theory. On-line Information Review, 38(5), 598-615.

Martín-Consuegra, D., Díaz, E., Gómez, M., \& Molina, A. (2019). Examining consumer luxury brand-related behavior intentions in a social media context: The moderating role of hedonic and utilitarian motivations. Physiology \& behavior, 200, 104-110.

Marx, K. (2013). O capital: crítica da economia política. Livro I: O processo de produção do capital. São Paulo: Boitempo.

Orlikowski, W. J. (2009). The sociomateriality of organisational life: considering technology in management research. Cambridge Journal of Economics, 34, 125-141.

Quan-Haase, A., \& Young, A. L. (2010). Uses and gratifications of social media: A comparison of Facebook and instant messaging. Bulletin of science, technology \& society, 30(5), 350-361.

Ritzer, G. (2015). Prosumer capitalism. The Sociological Quarterly, 56(3), 413-445.

Ritzer, G. (2014). Prosumption: Evolution, revolution, or eternal return of the same? Journal of Consumer Culture, 14(1), 3-24.

Ritzer, G., \& Jurgenson, N. (2010). Production, consumption, prosumption: The nature of capitalism in the age of the digital 'prosumer'. Journal of consumer culture, 10(1), 13-36. 
Stawarz, K., Preist, C., \& Coyle, D. (2019) Use of Smartphone Apps, Social Media, and Wed-Based Resources to Support Mental Health and Well-Being: Online Survey. JMIR Mental Health, 6(7), 1-14

Steyn, P., Wallström, Å., \& Pitt, L. (2010). Consumer-generated content and source effects in financial services advertising: An experimental study. Journal of Financial Services Marketing, 15(1), 49-61.

Tocqueville, A. (2014). A democracia na América. Leis e Costumes. São Paulo: Martins Fontes.

Turcotte, J., York, C., Irving, J., Scholl, R. M., Pingree, R. J. (2015). News recommendations from Social Media Opinion Leaders: Effects on Media Trust and Information Seeking. Journal of Computer-Mediated Communication, 20, 520-535. https://doi.org/10.1111/jcc4.12127.

Tuten, T. L., \& Solomon, M. R. (2017). Social media marketing. Newcastle, UK: Sage.

Uzunoğlu, E. \& Kip, S. M. (2014). Brand communication through digital influencers: Leveraging blogger engagement. International Journal of Information Management, 34(5), 592-602.

Van Dijck, J. (2012). Facebook as a tool for producing sociality and connectivity. Television \& New Media, 13(2), 160-176.

Vargo, S. L., \& Lusch, R. F. (2004). Evolving to a new dominant logic for marketing. Journal of marketing, 68(1), 1-17.

Viner, R. M. et al. (2019) Roles of cyberbullying, sleep, and physical activity in mediating the effects of social media use on mental health and wellbeing among young people in England: a secondary analysis of longitudinal data. The Lancet Child \& Adolescent Health, 3(10), 685-696.

Wang, P., Huang, Q., Davison, \& R. M. (2020). How do digital influencers affect social commerce intention? The roles of social power and satisfaction. Information Technology \& People, ahead-of-print. https://doi.org/10.1108/ITP-09-2019-0490.

Weimann, G. (1994). The influentials: People who influence people. London: SUNY Press.

Whitehead, A. N. (1985). Science and the modern world. London: Free Association Books.

Williams, D. L., Crittenden, V. L., Keo, T., \& McCarty, P. (2012). The use of social media: an exploratory study of usage among digital natives. Journal of Public Affairs, 12(2), 127-136.

Zheng, Y., Yang, X., Zhou, R., Niu, G., Liu, Q., \& Zhou, Z. (2020). Upward social comparison and state anxiety as mediators between passive social network site usage and online compulsive buying among women. Addictive Behaviors, 111(12), 1-7. 